\title{
Antihyperglycemic and antioxidant potential of oil from Arachis hypogaea L. in streptozotocin-nicotinamide induced diabetic rats
}

\author{
Manoj Kumar ${ }^{1}$, Sunil Sharma ${ }^{1}$ and Neeru Vasudeva ${ }^{2 \star}$ \\ ${ }^{1}$ Department of Pharmaceutical Sciences, Guru Jambheshwar University of Science and Technology, Hisar, Haryana- \\ 125001, India. \\ ${ }^{2}$ Pharmacology Divisions, Department of Pharmaceutical Sciences, Guru Jambheshwar University of Science and \\ Technology, Post Box: 38, Hisar-125001, India.
}

Accepted 14 August, 2013

\begin{abstract}
In this investigation, antihyperglycemic and antioxidant potential of oil of seeds of Arachis hypogaea (AHO) in streptozotocin-nicotinamide (STZ) induced type 2 diabetic rats was observed along with gas chromatography flame ionization detector (GC-FID) analysis. AHO was orally administered to diabetic rats to study its effect in both acute and chronic antihyperglycemic study. The body weight, oral glucose tolerance test and biochemical parameters: glucose level, insulin level, liver glycogen content, glycosylated hemoglobin and antioxidant parameters were estimated for all treated groups and compared against diabetic control group. GC-FID analysis showed the presence of major constituents as oleic acid $(48.4500 \%)$, linoleic acid $(32.6355 \%)$, palmitic acid $(12.6988 \%)$ and arachidic acid $(4.0814 \%)$. AHO (500 and $1000 \mathrm{mg} / \mathrm{kg})$ and glibenclamide $(0.6 \mathrm{mg} / \mathrm{kg})$ in respective groups of diabetic animals administered for 28 days reduced the blood glucose level in streptozotocin-nicotinamide induced diabetic rats. There was significant increase in body weight, liver glycogen content, plasma insulin level and decrease in the blood glucose and glycosylated hemoglobin in test groups as compared to control group. In vivo antioxidant studies on STZ-nicotinamide induced diabetic rats revealed decreased malondialdehyde (MDA) and increased reduced glutathione (GSH). Thus the investigation results that oil of seeds of $\boldsymbol{A}$ hypogaea have significant antihyperglycemic and antioxidant activity.
\end{abstract}

Key words: Seeds, Streptozotocin, Essential oil, MDA.

\section{INTRODUCTION}

Nowadays, herbal remedies have become the popular source of medicines due to lesser adverse reactions (Kumar et al., 2012) and various other reasons. There are thousands of plants used over centuries for the treatment of various diseases. Species of the genus Arachis is one of the important medicinal plants used in various systems of medicine (Velisek et al., 1995). Peanut (Arachis hypogaea L.) is one of the world's most important legumes which is grown primarily for its high quality edible oil and protein. It is an important legume Africa (SA) (Reddy et al., 2003). Peanut is an annual herbaceous plant growing 30 to $50 \mathrm{~cm}$ tall (Sharma et al., 2000). Diabetes is growing with a high speed in India and has become a capital of the world which is affecting all age groups of people (Mohan et al., 2007). There were an estimated 40 million persons with 
diabetes in India in 2007 and this number is predicted to rise to almost 70 million people by 2025 according to Diabetes Atlas published by the International Diabetes Federation (IDF) (Kumar et al., 2012). The country with the largest number of diabetic people will be India by 2030.

Due to these sheer numbers, the economic burden due to diabetes in India is amongst the highest in the world (Sicree et al., 2006). Diabetes is of mainly three types: Type I, type II, and Gestational. Type II diabetes is the most common type, accounting for 90 to $95 \%$ of all diabetic cases. So the main concern for management of this type of diabetes is very essential. Some studies have suggested that essential oils may be useful in the treatment of type II diabetes mellitus and various oils have been used as therapeutic agents for years without any significant adverse health effects (Pandey et al., 2011). Peanuts contain monounsaturated and polyunsaturated fats that keep the heart healthy. A good level of both monounsaturated and polyunsaturated fats results in lowering blood cholesterol levels, and thereby reducing the risk of coronary heart diseases. It is used as a high source of plant protein. The antioxidant polyphenols, primarily a compound called p-coumaric acid and oleic acid not only protect the heart but inhibit the growth of free radicals, keeping infection at bay. It is also a rich source of minerals like magnesium, phosphorus, potassium, zinc, calcium, sodium, etc; thus ensuring a healthy heart and ensuring minimized risk of mineral deficient diseases (Yen et al., 2005).

The seed oil of peanut has been widely used in the food industries from centuries. As far as we know, the effect of oil on antihyperglycemic and antioxidant potential in diabetic animal models has not been investigated scientifically till date. In light of these findings, we carried out this study for the evaluation of antihyperglycemic and antioxidant potential of oil of seeds of $A$. hypogaea.

\section{MATERIALS AND METHODS}

\section{Drugs and chemicals}

The chemicals and reagents used in the study were glibenclamide (Torrent Pharmaceutical, Ahmadabad), streptozotocin, heparin (SRL, India), ethylenediaminetetraacetic acid (EDTA) (Hi-media Lab. Pvt Ltd., Mumbai, India), Ellman's reagent (5,5'-dithiobis-(2nitro-benzoic acid); DTNB), sodium sulphate, methanol, pyridine, anthrone, thiourea, benzoic acid, sodium chloride (SD Fine Chem Ltd., Mumbai, India). All the chemicals used in the study were of analytical grade.

\section{Isolation of oil}

The dried seeds of $A$. hypogaea were purchased from oil and seed section of Chaudhary Charan Singh Haryana Agriculture University, Hisar, India. The seeds were crushed and oil was extracted with the help of Clevenger apparatus using hydrodistillation (with water) technique using $4 \mathrm{~kg}$ of seeds. The percentage yield of light yellow colored oil was found to be $42 \% \mathrm{w} / \mathrm{v}$.

\section{Experimental animals}

Healthy albino wistar rats (150 to $250 \mathrm{~g}$ ) were procured from Disease Free Small Animal House, Lala Lajpat Rai University of Veterinary and Animal Sciences, Hisar (Haryana). The rats were housed in polycarbonate cages (size: $29 \times 22 \times 14 \mathrm{~cm}$ ) under standard laboratory conditions $\left(25 \pm 3^{\circ} \mathrm{C}\right.$ : 35 to $60 \%$ humidity) with alternating light and dark cycle of $12 \mathrm{~h}$ each, and were feed fed with a standard rat pellet diet (Hindustan Lever Ltd, Mumbai, India) and water ad libitum. The experimental protocol was approved by Institutional Animals Ethics Committee (IAEC), and animal care was taken as per the guidelines of Committee for the Purpose of Control and Supervision of Experiments on Animals (CPCSEA), Govt. of India (Registration No. 0436).

Gas chromatography flame ionization detector (GC- FID) analysis

Methyl ester analysis was performed on NUCON (Nucon Engineers, New Delhi Company, model no-5700) gas chromatograph using column (10\% FFAP). The carrier gas used was nitrogen at a flow rate of $30 \mathrm{ml} / \mathrm{min}$. The oven temperature was kept at $60^{\circ} \mathrm{C}$ for $1 \mathrm{~min}$ programmed to $220^{\circ} \mathrm{C}$ at a rate of $6^{\circ} \mathrm{C} / \mathrm{min}$ and kept at $200^{\circ} \mathrm{C}$ for $3 \mathrm{~min}$. Hydrogen flow rate was $30 \mathrm{ml} / \mathrm{min}$, air flow rate was $300 \mathrm{ml} / \mathrm{min}$. The injection volume was $1 \mu \mathrm{l}$. Detector used was flame ionization detector and detector temperature was $220^{\circ} \mathrm{C}$.

\section{Induction of diabetes}

Type II diabetes mellitus (NIDDM) was induced in overnight fasted animals by a single intraperitoneal injection of $50 \mathrm{mg} / \mathrm{kg} \mathrm{STZ} \mathrm{in} 0.1$ $M$ citrate buffer ( $\mathrm{pH}: 4.5)$ in a volume of $1 \mathrm{ml} / \mathrm{kg}$ body weight $15 \mathrm{~min}$ after the i.p. administration of $110 \mathrm{mg} / \mathrm{kg}$ nicotinamide. Diabetes was developed and stabilized over a period of 7 days. Diabetes was confirmed by the elevated blood glucose levels determined at $72 \mathrm{~h}$ and on 7th day after injection. Only rats confirmed with permanent NIDDM (Glucose level above $250 \mathrm{mg} / \mathrm{dl}$ ) were used in the study. Blood was collected by intraocular route (Marudamuthu et al., 2008).

\section{Experimental design}

Rats were divided into the following groups comprising six rats in each group after the induction and confirmation of diabetes.

\section{For acute antihyperglycemic model}

The diabetes induced rats were used for the acute antihyperglycemic study which was carried out for a period of $4 \mathrm{~h}$ to check whether the oil have some effect or not. Five groups of animals were taken and labeled as Group 1: Normal rats; Group 2: Diabetic control; Group 3: Diabetic animals were administered glibenclamide (0.6 mg/kg p.o); Group 4: Diabetic animal were administered orally $500 \mathrm{mg} / \mathrm{kg}$ of AHO; Group 5: Diabetic animal were administered orally $1000 \mathrm{mg} / \mathrm{kg}$ of $\mathrm{AHO}$. 


\section{For chronic antihyperglycemic model}

In the chronic antihyperglycemic models the study was carried out for 28 days to study the various parameters of the diabetes to confirm the antihyperglycemic activity of $\mathrm{AHO}$ in streptozotocin induced diabetes in rats. The chronic study was performed in the same pattern of animal groups as in the acute chronic antihyperglycemic model except the time period. The animal groups prepared were as Group 1: Normal rats; Group 2: Diabetic control; Group 3: Diabetic animals administered glibenclamide $(0.6 \mathrm{mg} / \mathrm{kg} \mathrm{p.o})$; Group 4: Diabetic animal administered orally $500 \mathrm{mg} / \mathrm{kg}$ of $\mathrm{AHO}$; Group 5: Diabetic animal administered orally $1000 \mathrm{mg} / \mathrm{kg}$ of $\mathrm{AHO}$.

\section{Blood sample collection}

The $24 \mathrm{~h}$ fasted animals were sacrificed by cervical decapitation on 28th day of treatment. The trunk was cut with the scissors and blood was collected in heparinized tubes. The plasma was obtained by centrifugation at $5,000 \mathrm{rpm}$ for $5 \mathrm{~min}$ for the determination of biochemical parameters; glucose, insulin, cholesterol etc.

\section{Estimation of plasma glucose and cholesterol}

Plasma cholesterol and glucose level were measured by commercial supplied biological kit Erba Glucose Kit (GOD-POD Method) and Erba Cholesterol Kit (CHOD-PAP Method), respectively using Auto-analyser (Chem 5 Plus- $V_{2}$, Erba Mannhein, Germany) in plasma sample prepared as above. Glucose and cholesterol values were expressed as $\mathrm{mg} / \mathrm{dl}$ blood sample.

\section{Estimation of glycosylated hemoglobin (Hb1 Ac)}

Glycosylated hemoglobin was measured using commercial supplied biological kit (Erba Diagnostic) in plasma sample prepared as above using Chem 5 Plus- $V_{2}$ Auto-analyser (Erba Mannhein Germany). Values were expressed as the percentage of total hemoglobin.

\section{Estimation of liver glycogen content}

Liver glycogen estimation was performed as described by Morris et al. (1948). Immediately after excision from the animal, $1 \mathrm{~g}$ of the liver was dropped into a previously weighed test tube containing 3 $\mathrm{ml}$ of $30 \%$ potassium hydroxide solution. The weight of the liver sample was determined. The tissue was then digested by heating the tube for $20 \mathrm{~min}$ in boiling water bath, and following this the digest was cooled, transferred quantitatively to a $50 \mathrm{ml}$ volumetric flask, and diluted to the mark with water. The contents of the flask were then thoroughly mixed and a measured portion was then further diluted with water in a second volumetric flask so as to yield a solution of glycogen of 3 to $30 \mu \mathrm{g} / \mathrm{ml}$. Five $\mathrm{ml}$ aliquots of the final dilution were then pipetted into Evelyn tube and the determination with anthrone was carried out. The amount of glycogen in the aliquot used was then calculated using the following equation:

$\mu \mathrm{g}$ of glycogen in aliquot $=100 \mathrm{U} / 1.11 \mathrm{~S}$

$\mathrm{U}$ is the optical density of unknown solution. $\mathrm{S}$ is the optical density of the $100 \mu \mathrm{g}$ glucose and 1.11 is the factor determined by for the conversion of the glucose to the glycogen (Seifter et al., 1950).

\section{In vivo antioxidant activity}

\section{Estimation of MDA level}

Malondialdehyde (MDA), an index of free radical generation/lipid peroxidation, was determined as described (Okhawa et al., 1979). Briefly, the reaction mixture consisted of $0.2 \mathrm{ml}$ of $8.1 \%$ sodium lauryl sulphate, $1.5 \mathrm{ml}$ of $20 \%$ acetic acid $(\mathrm{pH} \mathrm{3.5)}$ and $1.5 \mathrm{ml}$ of $0.8 \%$ aqueous solution of thiobarbituric acid added to $0.2 \mathrm{ml}$ of blood plasma. The mixture was made up to $4 \mathrm{ml}$ with distilled water and heated at $95^{\circ} \mathrm{C}$ for $60 \mathrm{~min}$. After cooling the contents under running tap water, $5 \mathrm{ml}$ of $\mathrm{n}$-butanol and pyridine $(15: 1 \mathrm{v} / \mathrm{v})$ and $1 \mathrm{ml}$ of distilled water was added. The contents were centrifuged at about 3,000 rpm for $10 \mathrm{~min}$. The organic layer was separated out and its absorbance was measured at $532 \mathrm{~nm}$ using a double beam UV-Visible spectrophotometer (Systronics 2203, Bangalore, India) against an appropriate blank. MDA values were calculated using the extinction coefficient of MDA-thiobarbituric acid complex $1.56 \times$ $10^{5} \mathrm{~L} / \mathrm{mol} \mathrm{cm}$ and expressed as $\mathrm{nmol} / \mathrm{ml}$.

\section{Estimation of reduced glutathione level}

The liver samples $(200 \mathrm{mg})$ were homogenized in $8 \mathrm{ml}$ of $0.02 \mathrm{M}$ EDTA in an ice bath. The homogenates were kept in the ice bath until used. Aliquots of $5 \mathrm{ml}$ of the homogenates were mixed in $15 \mathrm{ml}$ test tubes with $4.0 \mathrm{ml}$ distilled water and $1 \mathrm{ml}$ of $50 \%$ trichloroacetic acid (TCA). The tubes were centrifuged for $15 \mathrm{~min}$ at approximately $3,000 \mathrm{rpm}, 2 \mathrm{ml}$ of supernatant was mixed with $4 \mathrm{ml}$ of $0.4 \mathrm{M}$ Tris buffer pH 8.9, $0.1 \mathrm{ml}$ Ellman's reagent [5,5-dithiobis-(2-nitro-benzoic acid)] (DTNB) added and the sample shaken. The absorbance was read within 5 min of the addition of DTNB at $412 \mathrm{~nm}$ against a reagent blank with no homogenate. Results are expressed as $\mu \mathrm{mol}$ $\mathrm{GSH} / \mathrm{g}$ tissue.

\section{Statistical analysis}

The data for various biochemical parameters were evaluated by use of one-way analysis of variance (ANOVA), followed by Dunnett's test using the software Sigma-Stat 3 (Version 3). In all the tests, the criterion for statistical significance was $p<0.05$.

\section{RESULTS}

\section{Components of AHO}

GC-FID analysis showed the presence of stearic acid $(1.2 \%)$, oleic acid $(48.45 \%)$, linoleic acid $(32.63 \%)$, behenic acid $(0.93 \%)$, palmitic acid $(12.69 \%)$, and arachidic acid (4.08\%) (Table 1 and Figure 1 ).

\section{Oral glucose tolerance test}

The effect of $\mathrm{AHO}$ on plasma glucose level after glucose feeding of $2 \mathrm{~g} / \mathrm{kg}$ body weight orally to the STZ diabetic rats is expressed in Table 2. The blood glucose level rose to a maximum in $60 \mathrm{~min}$ after glucose loading. The oil (500 and $1000 \mathrm{mg} / \mathrm{kg}$ body weight) treated groups 


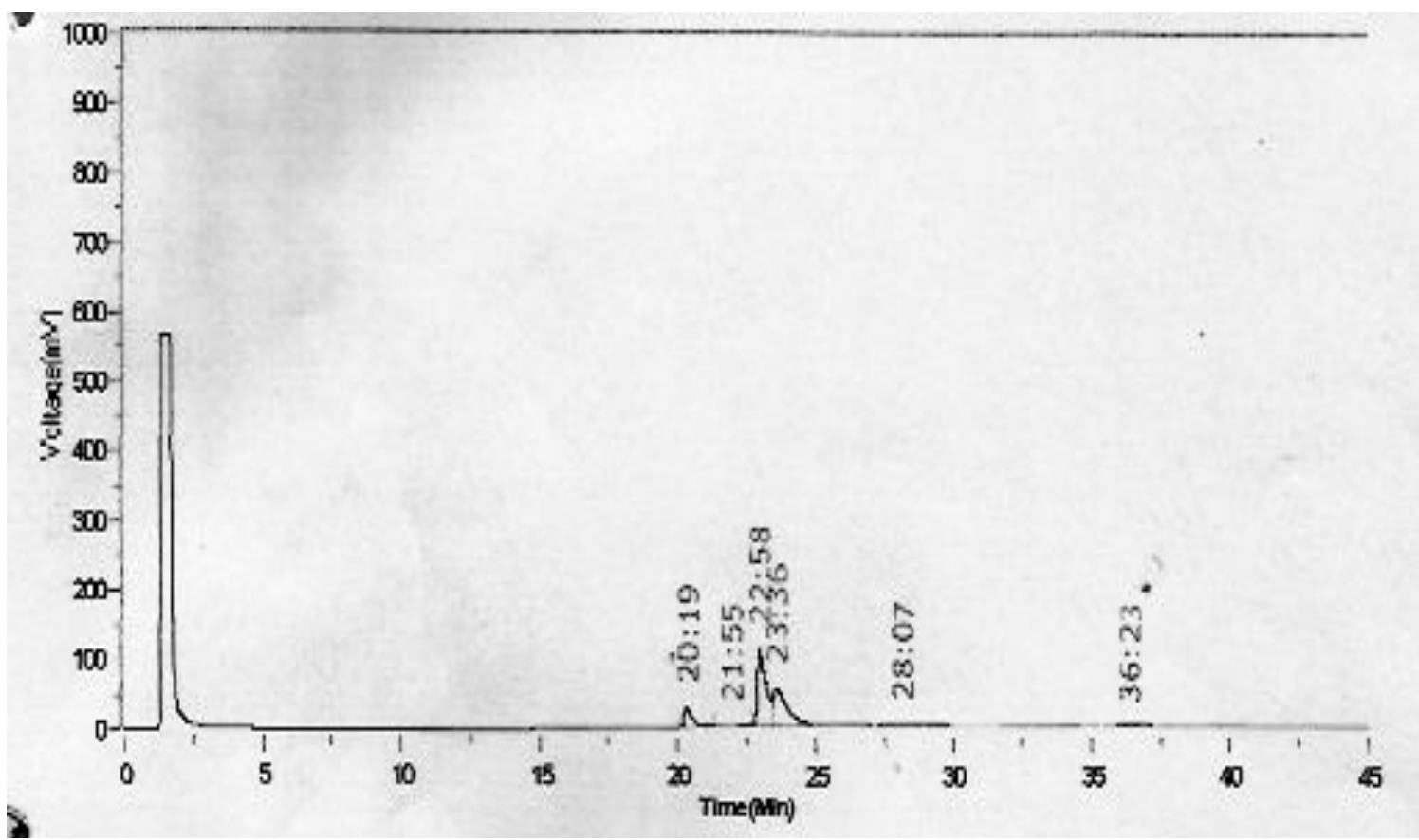

Figure 1. GC-FID chromatogram of oil from Arachis hypogaea.

Table 1. Components of Arachis hypogaea oil by using GC-FID

\begin{tabular}{lll}
\hline S/No & Name of constituent & Percentage (\%) \\
\hline 1 & Stearic acid & 1.2036 \\
2 & Oleic acid & 48.4500 \\
3 & Linoleic acid & 32.6355 \\
4 & Behenic acid & 0.9307 \\
5 & Palmitic acid & 12.6988 \\
6 & Arachidic acid & 4.0814 \\
\hline
\end{tabular}

showed a significant decrease in level of glucose as compared to control group. The oil treated group showed a marked fall in glucose level in 90 to 120 min interval (Table 1).

\section{Effect of AHO on STZ diabetic rats in acute hyperglycemia study}

Administration of $\mathrm{AHO}$ at a dose $500 \mathrm{mg} / \mathrm{kg}$ body weight p.o. to STZ diabetic rats showed reduction in blood glucose level from 342 to $277 \mathrm{mg} / \mathrm{dl}$ at 4 th hour. When the dose was increased as $1000 \mathrm{mg} / \mathrm{kg}$ then the blood glucose level decreased from 334 to $260 \mathrm{mg} / \mathrm{dl}$ which was found significant $(p<0.01)$ when compared with diabetic control (Table 3).

\section{Effect of AHO on STZ diabetic rats in chronic study}

In chronic study, administration of $\mathrm{AHO}$ at the dose of $500 \mathrm{mg} / \mathrm{kg}$ body weight to STZ diabetic rats for 28 days showed a fall in plasma glucose level from 355 to 194 $\mathrm{mg} / \mathrm{dl}$ on 28th day when compared to 0 day values. AHO at the dose of $1000 \mathrm{mg} / \mathrm{kg}$ body weight showed a significant $(p<0.01)$ fall in plasma glucose level from 365 to $156 \mathrm{mg} / \mathrm{dll}$ on 28th day (Table 4).

\section{Effect of AHO on body weight}

An increase in the body weight of normal rats was observed whereas the weight of diabetic control rats decreased from day 1 to day 28 . AHO at the dose of 500 and $1000 \mathrm{mg} / \mathrm{kg}$ body weight, respectively groups when administered to diabetic rats showed a significant increase in body weight as compared to the diabetic control group $(p<0.01)$ (Table 5).

\section{Effect of AHO on insulin level}

Table 5 shows the level of plasma insulin in the control and experimental groups of rats. Diabetic rats showed a significant decrease in plasma insulin compared with normal rats. Following oral administration of $\mathrm{AHO}$, plasma insulin level increased when compared to control rats (Table 6). 
Table 2. Effect of $A$. hypogaea oil in oral glucose tolerance test (OGTT).

\begin{tabular}{|c|c|c|c|c|c|c|}
\hline \multirow{2}{*}{ Treatment } & \multirow{2}{*}{ Dose } & \multicolumn{5}{|c|}{ Mean blood glucose concentration (mg/dl) \pm S.E.M } \\
\hline & & $0 \mathrm{~min}$ & $30 \mathrm{~min}$ & $60 \mathrm{~min}$ & $90 \mathrm{~min}$ & $120 \mathrm{~min}$ \\
\hline Normal & ---- & $80 \pm 2.6$ & $87 \pm 2.8$ & $90 \pm 3.8$ & $86 \pm 2.5$ & $83 \pm 2.7$ \\
\hline Diabetic control & ---- & $290 \pm 4.6$ & $390 \pm 5.3$ & $413.2 \pm 4.3$ & $360 \pm 2.7$ & $331 \pm 2.8$ \\
\hline $\mathrm{AHO}$ & $500 \mathrm{mg} / \mathrm{kg}$ & $277 \pm 4.8$ & $299 \pm 3.9$ & $344 \pm 7.2$ & $265 \pm 7.6^{\star *}$ & $256 \pm 4.9^{* *}$ \\
\hline $\mathrm{AHO}$ & $1000 \mathrm{mg} / \mathrm{kg}$ & $288 \pm 6.5$ & $321 \pm 5.5$ & $388 \pm 4.9$ & $260 \pm 3.8^{\star *}$ & $232 \pm 7.3^{\star \star}$ \\
\hline
\end{tabular}

Values are presented as mean $\pm \mathrm{SEM} ; \mathrm{n}=6$ in each group. One way ANOVA followed by Dunnett's test ${ }^{* *} \mathrm{p}<0.01$ vs. diabetic control; AHO: Oil of seeds of Arachis hypogaea.

Table 3. Effect of Arachis hypogaea oil in STZ induced diabetic rats in acute antihyperglycemic study.

\begin{tabular}{lcccccc}
\hline \multirow{2}{*}{ Treatment } & \multirow{2}{*}{ Dose } & \multicolumn{5}{c}{ Mean blood glucose concentration (mg/dl) \pm SEM) } \\
\cline { 3 - 7 } & & $\mathbf{0 ~ h}$ & $\mathbf{1 / 2} \mathbf{~ h}$ & $\mathbf{1} \mathbf{~ h}$ & $\mathbf{2} \mathbf{~ h}$ & $\mathbf{4} \mathbf{~}$ \\
\hline Normal & -- & $76 \pm 4.2$ & $80 \pm 3.2$ & $77 \pm 2.5$ & $82 \pm 4.1$ & $79 \pm 5.3$ \\
Control & -- & $340.5 \pm 10.2$ & $342 \pm 11.3$ & $346 \pm 7.6$ & $341.0 \pm 6.7$ & $332.0 \pm 7.2$ \\
AHO & $500 \mathrm{mg} / \mathrm{kg} \mathrm{p.0}$ & $342 \pm 8.7$ & $323.1 \pm 6.4$ & $299 \pm 5.6^{\star *}$ & $284 \pm 4.4^{\star \star}$ & $277 \pm 6.6^{\star *}$ \\
AHO & $1000 \mathrm{mg} / \mathrm{kg} \mathrm{p.0}$ & $334 \pm 8.2$ & $310 \pm 4.6^{*}$ & $290 \pm 3.2^{\star *}$ & $260 \pm 3.5^{\star *}$ & $265 \pm 4.5^{\star *}$ \\
\hline
\end{tabular}

Values are presented as mean \pm S.E.M.; $n=6$ in each group. One way ANOVA followed by Dunnett's test ${ }^{*} p<0.05 ;{ }^{* *} p<0.01$ vs. diabetic control; AHO: Oil of seeds of Arachis hypogaea.

Table 4. Effect of Arachis hypogaea oil in STZ induced diabetic rats in chronic antihyperglycemic study.

\begin{tabular}{lcccccc}
\hline \multirow{2}{*}{ Treatment } & \multirow{2}{*}{ Dose } & \multicolumn{5}{c}{ Mean blood glucose concentration (mg/dl) \pm S.E.M } \\
\cline { 3 - 6 } & & 0th day & 7th day & 14th day & 2st day & 28 $^{\text {th }}$ day \\
\hline Normal & -- & $80 \pm 4.2$ & $79 \pm 3.2$ & $82 \pm 2.5$ & $85.5 \pm 4.1$ & $78 \pm 2.1$ \\
Control & -- & $380 \pm 7.3$ & $379 \pm 7.6$ & $384 \pm 6.7$ & $416 \pm 7.2$ & $410 \pm 5.4$ \\
$\mathrm{AHO}$ & $500 \mathrm{mg} / \mathrm{kg} \mathrm{p.0}$ & $355 \pm 9.4$ & $277 \pm 9.8^{* *}$ & $256 \pm 4.2^{* *}$ & $235 \pm 7.2^{* *}$ & $194 \pm 7.8^{\star *}$ \\
$\mathrm{AHO}$ & $1000 \mathrm{mg} / \mathrm{kg} \mathrm{p.0}$ & $365 \pm 8.4$ & $256 \pm 7.8^{* *}$ & $234 \pm 4.8^{* *}$ & $201 \pm 5.4^{* *}$ & $156 \pm 6.6^{* *}$ \\
\hline
\end{tabular}

Values are presented as mean $\pm \mathrm{SEM} ; \mathrm{n}=6$ in each group. One way ANOVA followed by Dunnett's test ${ }^{* *} p<0.01$ vs. diabetic control; AHO: Oil of seeds of Arachis hypogaea.

Table 5. Effect of Arachis hypogaea oil on body weight in diabetic rats

\begin{tabular}{llcccc}
\hline S/No & Treatment & Dose & $\begin{array}{c}\text { Initial body } \\
\text { weight }(\mathbf{g})\end{array}$ & $\begin{array}{c}\text { Final body } \\
\text { weight }(\mathbf{g})\end{array}$ & Change in weight \\
\hline 1 & Normal & -- & $220 \pm 1.1$ & $240 \pm 1.5$ & +20 \\
2 & Diabetic control & -- & $215 \pm 1.8$ & $194 \pm 2.0$ & $-21^{\text {a }}$ \\
3 & AHO & $500 \mathrm{mg} / \mathrm{kg} \mathrm{p.0}$ & $250 \pm 2.2$ & $260 \pm 1.0$ & $+10^{* *}$ \\
4 & AHO & $1000 \mathrm{mg} / \mathrm{kg} \mathrm{p.O}$ & $240 \pm 1.3$ & $260 \pm 1.4$ & $+20^{* *}$ \\
\hline
\end{tabular}

Values are presented as mean \pm S.E.M.; $n=6$ in each group. One way ANOVA followed by Dunnett's test ${ }^{a} p<0.01$ vs. normal; ${ }^{* *} \mathrm{p}<0.01$ vs. diabetic control; AHO: Oil of seeds of Arachis hypogaea.

\section{Effect of AHO on glycosylated hemoglobin (HbA1c)}

The effect of $\mathrm{AHO}$ on $\mathrm{HbA1c}$ in STZ diabetic rats is shown in Table 6. The level of glycosylated hemoglobin significantly increased $(p<0.01)$ in diabetic rats as compared to normal control group. The diabetic rats 
Table 6. Effect of Arachis hypogaea oil on glycosylated hemoglobin (HbA1c), hepatic glycogen and insulin in the study.

\begin{tabular}{lcccc}
\hline Treatment & Dose & HbA1c $(\%$ of Hb) & Hepatic glycogen $(\mathbf{m g} / \mathbf{g}$ wt of tissue) & Insulin (micro U/ml) \\
\hline Normal & -- & $6 \pm 1.4$ & $74 \pm 6.6$ & $14 \pm 2.1$ \\
Diabetic Control & -- & $11.3 \pm 2.4^{\mathrm{a}}$ & $27 \pm 4.5^{\mathrm{a}}$ & $7.9 \pm 1.1^{\mathrm{a}}$ \\
$\mathrm{AHO}$ & $500 \mathrm{mg} / \mathrm{kg}$ & $9 \pm 1.1$ & $50 \pm 2.3^{\star}$ & $10 \pm 1.2$ \\
$\mathrm{AHO}$ & $1000 \mathrm{mg} / \mathrm{kg}$ & $7.3 \pm 1.3^{* *}$ & $66 \pm 3.2^{* *}$ & $12.1 \pm 2.5^{\star}$ \\
\hline
\end{tabular}

Values are presented as mean \pm S.E.M; $n=6$ in each group. One way ANOVA followed by Dunnett's test ${ }^{a} p<0.01$ vs. normal; ${ }^{*} p<$ $0.05 ;{ }^{* \star} \mathrm{p}<0.01$ vs. diabetic control; AHO: Oil of seeds of Arachis hypogaea.

Table 7. Effect of Arachis hypogaea oil on lipid profile.

\begin{tabular}{lcccc}
\hline Treatment & Dose & Cholesterol $(\mathbf{m g} / \mathbf{d l})$ & Triglyceride $(\mathbf{m g} / \mathbf{d l})$ & HDL $(\mathbf{m g} / \mathbf{d l})$ \\
\hline Normal & -- & $85 \pm 1.5$ & $16 \pm 2.5$ & $66 \pm 1.9$ \\
Diabetic Control & -- & $232 \pm 2.4^{\mathrm{a}}$ & $43 \pm 3.1^{\mathrm{a}}$ & $37.4 \pm 1.2^{\mathrm{a}}$ \\
$\mathrm{AHO}$ & $500 \mathrm{mg} / \mathrm{kg}$ & $180 \pm 2.2^{\star *}$ & $32 \pm 1.1^{\star *}$ & $46 \pm 2.1^{*}$ \\
$\mathrm{AHO}$ & $1000 \mathrm{mg} / \mathrm{kg}$ & $106 \pm 2.3^{\star *}$ & $21 \pm 1.0^{\star *}$ & $58 \pm 1.2^{*}$ \\
\hline
\end{tabular}

Values are presented as mean \pm S.E.M; $n=6$ in each group. One way ANOVA followed by Dunnett's test ${ }^{2}$ $\mathrm{p}<0.01$ vs. normal; ${ }^{*} \mathrm{p}<0.05 ;{ }^{* *} \mathrm{p}<0.01$ vs. diabetic control; AHO: Oil of seeds of Arachis hypogaea.

Table 8. Effect of Arachis hypogaea oil on antioxidant parameters (MDA and GSH).

\begin{tabular}{lccc}
\hline Treatment & Dose & MDA $(\mathbf{n m o l} / \mathbf{d l})$ & GSH $(\boldsymbol{\mu m o l} / \mathbf{g})$ \\
\hline Normal & -- & $2.8 \pm 0.2$ & $41.2 \pm 2.8$ \\
Diabetic Control & -- & $5.4 \pm 0.4^{\mathrm{a}}$ & $14 \pm 1.15^{\mathrm{a}}$ \\
$\mathrm{AHO}$ & $500 \mathrm{mg} / \mathrm{kg}$ & $3.6 \pm 0.6$ & $22 \pm 1.4$ \\
$\mathrm{AHO}$ & $1000 \mathrm{mg} / \mathrm{kg}$ & $3.0 \pm 0.1^{\star *}$ & $34 \pm 1.2^{\star *}$ \\
\hline
\end{tabular}

Values are presented as mean \pm S.E.M; $n=6$ in each group. One way ANOVA followed by Dunnett's test ${ }^{a} p<0.01$ vs. normal; ${ }^{* *} p<0.01$ vs. diabetic control; AHO: Oil of seeds of Arachis hypogaea

when treated with $\mathrm{AHO}$ for 28 days showed a significant $(\mathrm{p}<0.01)$ decreased level of glycosylated $\mathrm{Hb}$ as compared to untreated diabetic group (Table 6).

\section{Effect of AHO on hepatic glycogen content}

The hepatic glycogen content in diabetic rats decreased sharply as compared to control animal (Table 6). After chronic administration of $\mathrm{AHO}$ to diabetic rats, a significant increased $(p<0.01)$ liver glycogen content as compared to diabetic control group was observed.

\section{Effect of AHO on lipid profile}

Table 7 shows the level of lipids in normal and tested animals. There was a significant decrease in the level of HDL-cholesterol and a significant increase in the levels of total cholesterol and triglycerides in diabetic rats when compared to normal rats. The administration of $\mathrm{AHO}$ reversed the level of lipids significantly $(p<0.05$ and $p<$ 0.01).

\section{Effect of AHO on in vivo antioxidant parameters}

The data depicted in Table 8 shows the effect of oil on plasma malondialdehyde and reduced glutathione level. Plasma MDA level was found to be significantly higher in STZ diabetic rats compared to normal rats. The oil at dose $1000 \mathrm{mg} / \mathrm{kg}$ body weight p.o significantly reduced the level of MDA in diabetic rats. Plasma GSH level was found to be significantly lowered in STZ diabetic rats as compared to normal rats. The chronic administration of $\mathrm{AHO}$ at $1000 \mathrm{mg} / \mathrm{kg}$ body weight significantly increased the level of glutathione in diabetic rats. 


\section{DISCUSSION}

The aim of this study was to evaluate the antidiabetic and antioxidant potential of the AHO in STZ induced diabetic rats. Diabetes mellitus causes a disturbance in the uptake of glucose as well as glucose metabolism. A dose of STZ as low as $50 \mathrm{mg} / \mathrm{kg}$ produces an incomplete destruction of pancreatic beta cells and the rats become permanently diabetic (Aybar et al., 2001). After treatment with a low dose of STZ, many beta cells survive and regeneration is also possible (Gomes et al., 2001). Hyperglycemia generates high levels of free radicals by autoxidation of glucose and protein glycation, and oxidative stress has been reported to be a causative factor of cardiovascular complications in STZ-induced diabetes mellitus (Okutan et al., 2005).

Hyperglycemia is associated with the generation of reactive oxygen species (ROS) causing oxidative damage particularly to heart, kidney, eyes, nerves, liver, small and large vessels and gastrointestinal system (Tunali et al., 2006). The increased levels of plasma glucose in STZ-induced diabetic rats were lowered by $\mathrm{AHO}$ administration. The plasma glucose lowering activity was compared with glibenclamide, a standard hypoglycemic drug that stimulates insulin secretion from pancreatic beta cells (Tian et al., 1998). From the results of the present study, it appears that still insulin producing cells are functioning and the stimulation of insulin release could be responsible for most of the metabolic effects. It may be suggested that the mechanism of action of $\mathrm{AHO}$ is similar to glibenclamide. The glucose lowering activity of AHO may be related to both pancreatic (enhancement of insulin secretion) and extra pancreatic (peripheral utilization of glucose) mechanisms.

An increase in the level of glycosylated hemoglobin $(\mathrm{HbA} 1 \mathrm{c})$ in the diabetic control group of rats is due to the presence of large amount of blood glucose which reacts with hemoglobin to form glycosylated hemoglobin (Chattopadhyay, 1999). Oxidative stress increases due to the activation of transcription factors, advanced glycated end products (AGEs), and protein kinase C. If diabetes is persistent for long time, the glycosylated hemoglobin is found to increase (Sheela and Augusti, 1992). The level of $\mathrm{HbA}_{1} \mathrm{C}$ was decreased after the administration of $\mathrm{AHO}$ $1000 \mathrm{mg} / \mathrm{kg}$ as compared to diabetic control group $\left({ }^{\star *} \mathrm{p}<\right.$ 0.01).

In STZ induced diabetes mellitus, the loss of body weight is caused by increase in muscle wasting and catabolism of fat and proteins (Chakravarti et al., 1981). Due to insulin deficiency, protein content is decreased in muscular tissue by proteolysis (Swanston-Flatt et al., 1990). A decrease in body weight was registered in case of STZ diabetic control group rats while in tested groups the weight loss was reversed. Fatty acid mobilisation from adipose tissue is sensitive to insulin. Insulin's most potent action is the suppression of adipose tissue lipolysis (Campbell et al., 1992). A rise in plasma insulin concentration of only $5 \mathrm{IU} / \mathrm{ml}$ inhibits lipolysis by $50 \%$, whereas a reduction in basal insulin levels result in a marked acceleration of lipolysis (Bonadonna et al., 1990). We demonstrated that $\mathrm{AHO}$ increased plasma insulin concentrations in diabetic rats. Insulin levels higher than those of the control group may result in inhibition of lipolysis and decreased plasma triglyceride and cholesterol levels. Some studies suggest that the antihyperglycemic action of traditional antidiabetic plant extracts may be due in part to decreased glucose absorption in vivo (Gallagher et al., 2003). This mechanistic explanation may also apply to the actions of $\mathrm{AHO}$ in lowering the triglyceride and cholesterol level.

The conversion of glucose to glycogen in the liver cells is dependent on the extracellular glucose concentration and on the availability of insulin which stimulates glycogen synthesis over a wide range of glucose concentration (Sheela and Augusti, 1992). Diabetes reduces activity of glycogen synthase thereby affecting the glycogen storage and synthesis in rat liver and skeletal muscle (Kumar et al., 2011). Oral administration of $\mathrm{AHO} 1000 \mathrm{mg} / \mathrm{kg}$ body weight significantly increased hepatic glycogen levels in STZ diabetic rats possibly because of the reactivation of the glycogen synthase system as a result of increased insulin secretion. The antioxidant action of the oil may be due to the involvement of polyphenols like p-coumaric acid and oleic acid (Yen et al., 2005)

\section{Conclusion}

The present study showed that oral administration of AHO has potential antidiabetic and antioxidant effect in STZ induced diabetic rats. The potent antioxidant activity may be responsible for the antihyperglycemic effects. This investigation reveals the potential of $\mathrm{AHO}$ for use as a natural oral agent with antihyperglycemic and antioxidant effects.

\section{ACKNOWLEDGEMENT}

The authors are highly grateful to the University grant commission, Delhi (India) for providing research fellowship during research work. The authors have no conflict of interest.

\section{REFERENCES}

Aybar MJ, Riera ANS, Grau A, Sanchez SS (2001). Hypoglycemic effect of the water extract of Smallantus sonchifolius (yacon) leaves in normal and diabetic rats. J. Ethnopharmacol. 74:125-132.

Bonadonna RC, Groop LC, Zych K, Shank M, DeFronzo RA (1990). Dose dependent effect of insulin on plasma free fatty acid turnover 
and oxidation in humans. Am. J. Physiol. 259:736-750.

Campbell PJ, Carlson MG, Hill JO, Nurjhan N (1992). Regulation of free fatty acid metabolism by insulin in humans: role of lipolysis and reesterification. Am. J. Physiol. 263:1063-1069.

Chakravarti BK, Gupta S, Gambir SS, Gode KD (1981). Pancreatic betacell regeneration in rats by $(-)$ epicatechin. The Lancet. 2:759760.

Chattopadhyay RR (1999). Possible mechanism of antihyperglycemic effect of Azadirachta indica leaf extract. J. Ethanopharmacol. 67: 373-376.

Gallagher AM, Flatt PR, Duffy G, Abdel-Wahab YHA (2003). The effects of traditional antidiabetic plants on in vitro glucose diffusion. Nutr. Res. 23(3):413-424

Gomes A, Vedasiromoni, JR, Das M, Sharma RM, Ganguly DK (2001). Anti-hyperglycaemic effect of black tea (Camellia sinensis) in rat. $J$ Ethnopharmacol. 27: 243-275.

Kumar S, Kamboj J, Sharma S (2011). In vivo Anti-diabetic and Antioxidant potential of Psoralea corylifolia seeds in Streptozotocin induced type- 2 diabetic rats. J. Health Sci.57(3):1-11.

Kumar S, Singh R, Sharma S, Vasudeva N (2012). Acute and chronic animal models for the evaluation of anti-diabetic agents. Cardiovas Diabetol. 11:9.

Marudamuthu AS, Leelavinothan P (2008). Effect of pterostilbene on lipids and lipid profiles in Streptozotocin - Nicotinamide induced type 2 diabetes mellitus. J. Appl. Biomed. 6:31-37.

Mohan V, Sandeep S, Deepa R, Shah B, Varghese C (2007). Epidemiology of type 2 diabetes: Indian scenario. Indian J. Med. Res. 125:217-230.

Morris DL (1948). Quantitative determination of carbohydrates with drywood anthrone reagent. Science 107:254.

Okhawa H, Ohishi N, Yagi K (1979). Assay for lipid peroxides in anima tissue by thiobarbituric acid reaction. Anal. Biochem. 95:351-358.

Okutan H, Ozcelik N, Yilmaz HR, Uz E (2005). Effects of phenethyl ester on lipid peroxidation and anti oxidant enzymes in diabetic rat heart. Clin. Biochem. 38:191-196.

Pandey A, Tripathi P, Pandey R, Srivatava R, Goswami S (2011). Alternative therapies useful in the management of diabetes: A systematic review. J. Pharm. Biol. Appl. Sci. 3(4):504-512.

Reddy TY, Reddy VR, Anbumozhi V (2003). Physiological Responses of Groundnut (Arachis hypogea L.) To Drought Stress and Its Amelioration: A Critical Review. Plant Growth Regul. 41:75-88.
Seifter S, Dayton S, Molic B, Mutwzter E (1950). The estimation of glycogen with the anthrone reagent. In Arch. Biochem. 25(1):191200.

Sharma KK, Anjaiah V (2000). An efficient method for the production of transgenic plants of peanut (Arachis hypoaeae L.) through Agrobacterium tumefaciens-mediated genetic transformation. Plant Sci. 159:7-19.

Sheela GC, Augusti K (1992). Antidiabetic effects of S-allyl cystine sulphoxide isolated from garlic Allium sativum Linn. Indian J. Exp. Biol. 30:523-526.

Sicree R, Shaw J, Zimmet P (2006). Diabetes and impaired glucose tolerance. In: Gan D, editor. Diabetes Atlas. International Diabetes Federation. 3rd Ed. Belgium: 15-103.

Swanston-Flatt S, Day C, Bailey CJ, Flatt PR (1990). Traditional plant treatments for diabetes studies in normal and streptozotocin diabetic mice. Diabetologia 33:462-464.

Tian YM, Johnson G, Ashcroft JH (1998). Sulfonylureas enhance exocytosis from pancreatic b-cells by a mechanism that does not involve direct activation of protein kinase C. Diabetes. 47: 17221726.

Tunali S, Yanardag R (2006). Effect of vanadyl sulfate on the status of lipid parameters and on stomach and spleen tissues of streptozotocin-induced diabetic rats. Pharmacol Res. 53: 271-277.

Velisek J, Mikulcova R, Mikova K, Woldie KS, Link J, Davídek J (1995). Chemometric investigation of mustard seed. Lebenson Wiss Technol. 28(6):620-624

Yen WJ, Chang LW, Duh PD (2005). Antioxidant activity of peanut seed testa and its antioxidative component, ethyl protocatechuate. LWT Food Sci. Technol. 38(3): 193-200. 